\title{
Article
}

\section{A novel thermal imaging method for rapid screening of drug-polymer miscibility for solid dispersion based formulation development}

Muqdad Alhijjaj, Peter Belton, Laszlo Fabian, Nikolaus Wellner, Michael Reading, and Sheng Qi

Mol. Pharmaceutics, Just Accepted Manuscript • DOI: 10.1021/

acs.molpharmaceut.8b00798 • Publication Date (Web): 29 Oct 2018

Downloaded from http://pubs.acs.org on October 31, 2018

\section{Just Accepted}

"Just Accepted" manuscripts have been peer-reviewed and accepted for publication. They are posted online prior to technical editing, formatting for publication and author proofing. The American Chemical Society provides "Just Accepted" as a service to the research community to expedite the dissemination of scientific material as soon as possible after acceptance. "Just Accepted" manuscripts appear in full in PDF format accompanied by an HTML abstract. "Just Accepted" manuscripts have been fully peer reviewed, but should not be considered the official version of record. They are citable by the Digital Object Identifier (DOI®). "Just Accepted" is an optional service offered to authors. Therefore, the "Just Accepted" Web site may not include all articles that will be published in the journal. After a manuscript is technically edited and formatted, it will be removed from the "Just Accepted" Web site and published as an ASAP article. Note that technical editing may introduce minor changes to the manuscript text and/or graphics which could affect content, and all legal disclaimers and ethical guidelines that apply to the journal pertain. ACS cannot be held responsible for errors or consequences arising from the use of information contained in these "Just Accepted" manuscripts. 


\title{
A novel thermal imaging method for rapid screening of drug-polymer miscibility for solid dispersion based formulation development
}

\author{
Muqdad Alhijjaj ${ }^{1,2}$, Peter Belton ${ }^{3}$, László Fábián ${ }^{1}$, Nikolaus Wellner ${ }^{4}$, Mike Reading ${ }^{5}$ and \\ Sheng $\mathrm{Qi}^{{ }^{1 *}}$
}

1. School of Pharmacy, University of East Anglia, Norwich, Norfolk, NR4 7TJ, UK

2. College of Pharmacy, University of Basrah, Basrah, Iraq

3. School of Chemistry, University of East Anglia, Norwich, Norfolk, NR4 7TJ, UK

4. Quadram Institute Bioscience, Norwich Research Park, Colney, Norwich, Norfolk, NR4 7UA, UK

5. Cyversa, 12 Stanmore Road, Norwich, Norfolk, NR7 OHB, UK

Correspondence: Sheng Qi, sheng.qi@uea.ac.uk; Fax number: +44 1603592023 


\begin{abstract}
This study aimed to develop a rapid, simple and inexpensive screening method for selecting the best polymeric candidates possessing high active pharmaceutical ingredient (API) miscibility during the early stages of formulation development of solid dispersion based pharmaceutical products. A new thermal imaging based method, thermal analysis by structural characterization (TASC), was used as a thermoptometeric tool in conjunction with data analysis software to detect the melting point depression and post-melting dissolution of felodipine particles screened over thin spin-coated films of ten polymers commonly used in the pharmaceutical field. On the polymeric substrates the drug showed different degrees of melting point reduction, reflecting their different levels of polymer-drug miscibility. Using TASC to detect melting point depression is significantly (20-40 times) faster than the conventional DSC method without loss of the sensitivity of detection. The quantity of the material required for the screening is less than $1 / 1000^{\text {th }}$ of the material used in conventional DSC tests which significantly reduce the material wastage. Isothermal TASC tests and IR imaging confirmed the occurrence of thermal dissolution of the drug in the polymer for more miscible pairs. The real-time stability tests validate the accuracy of the polymer-drug miscibility screening results. These results demonstrate TASC as a promising screening tool for rapidly selecting the polymeric excipients for pharmaceutical formulations development.
\end{abstract}

Keywords: drug-polymer miscibility, melting point depression, thermal analysis by structural characterisation, solid dispersions, preformulation screening 


\section{Introduction}

Polymers are widely used in pharmaceutical solid dosage forms to form solid dispersions with the active pharmaceutical ingredients (APIs) to improve the in vivo dissolution and absorption of the drug ${ }^{1-4}$. In addition to being chemically compatible with the drug, the polymer should have good miscibility with the drug in the solid state to ensure good longterm physical stability over the shelf-life of the product. Accurate selection of the most suitable polymeric excipients in the preformulation stage can significantly help to reduce time and material waste and thus reduce the cost of developing new pharmaceutical solid dispersion based products.

There is a range of theoretical and experimental approaches used in practice for screening drug-polymer miscibility in the early stage of formulation development ${ }^{5-8}$. Theoretical miscibility prediction, for example using the solubility parameter is based on calculations which do not necessarily reflect the actual interaction between drugs and polymers ${ }^{5,}$ 7, 9 . Experimental confirmation is still needed and the results often deviate from the prediction. The most widely used miscibility prediction method is based on the combination of experimental testing and theoretical calculations. The method uses the DSC to measure the melting point depression of the crystalline drug due to the presence of the polymer reducing the chemical potential of the drug at melting $5,7,10,11$. The reduction of the chemical potential is an indicator of the drug-polymer miscibility. The data can be used to calculate the FloryHuggins interaction parameter and construct the drug-polymer miscibility phase diagram ${ }^{6,12-}$ 16. Although this method has proven to be more reliable than the solubility parameter calculation, there are two significant drawbacks of this approach. Firstly, it is extremely time consuming. Melting point depression is an excellent direct indicator for the miscibility between the drug and polymer, however the detection of the melting point depression is a 
highly kinetic process and heavily affected by the heating rate and highly sensitive to the homogeneity of the mixing between the drug and the polymer and drug to polymer ratio in the mixture (high drug to polymer ratios, more than $75 \% \mathrm{w} / \mathrm{w}$, are often required) ${ }^{12-14}$. The DSC measurements often need to be carried out using ultra slow heating rate $\left(0.5-1{ }^{\circ} \mathrm{C} / \mathrm{min}\right)$ to ensure the observation of the depression of drug melting. Secondly, when the FloryHuggins interaction parameters are calculated, the low temperature data (below the melting point of the drug) are extrapolated instead of experimentally measured which again creates ambiguity of the methodology and accuracy of the results ${ }^{17}$. Other experimental methods based on X-ray diffraction, infrared, Raman and terahertz spectroscopy and solid-state nuclear magnetic resonance have also been reported ${ }^{18-22}$. For these methods, the solid dispersions formulations of the drug in polymer were analysed instead of the physical mixtures used in the melting point depression method, which makes them highly timeconsuming and relying on highly specific instrumentation and expertise. While they can generate a significant amount of in-depth knowledge about molecular level interactions between the drug and the polymer, they are not suitable as a routine rapid screening method ${ }^{18-}$ 22.

This study demonstrates the development of a new rapid drug-polymer miscibility screening method based on measuring the melting point depression process. Thermal analysis by structural characterisation (TASC) is a recently developed thermal imaging tool that can be used to study thermal behaviour including melting and thermal dissolution ${ }^{23,24}$. This method detects any changes in the physical features of the regions of interests (ROIs). The detailed working principle of the TASC algorithm is described in our previous study ${ }^{23,24}$. In brief, the algorithm allows the quantification of changes in successive micrographs of samples when they are under thermal treatment (which could be heating, cooling or isothermal). Within a 
temperature programme scan, each pixel of the selected ROI region is subtracted from its precursor and the sum of the modulus of differences is calculated. Once the scan is completed, the minimum value for the sum of all differences obtained during the course of the scan is returned as the TASC values which are normalised with respect to the image when it shows no further change. For the application introduced in this study, the weight of the drug sample required is approximately $3-5 \mu \mathrm{g}$ in contrast to $\mathrm{mg}$ amount of the drug needed when DSC based methods are used. This significantly increases the sensitivity of detection of this new method in comparison to commonly used method such as DSC. In addition, previous studies showed that the thermal transition temperatures detected by TASC are much less sensitive to heating rate than DSC ${ }^{23,24}$. With high sensitivity and a weak dependence of the detected thermal transition on heating rate, this study aimed to develop TASC into a rapid and inexpensive screening method for drug-polymer miscibility. In this study, a $20{ }^{\circ} \mathrm{C} / \mathrm{min}$ heating rate was used, which improved the testing speed at least 20 times in comparison to the usual DSC measurements of melting point depression. As this method is a microscopic method, instead of using a bulk physical mixture of drug and polymer, the analysis only requires the observation of a single drug particle's melting behaviour in the presence of polymer. Polymer coated microscope slides were used as the solid substrate to sprinkle the drug particles on (although the data collection only requires a single drug particle). Figure 1 illustrates the procedure for a test on a single drug/polymer pair. In principle this process can be easily scaled up to screening multiple combinations of drug and polymer. To establish the foundation of this screening method, the analytical methodology was tested using a model drug, felodipine, and ten of the most commonly used pharmaceutical polymers as follows Soluplus, hypromellose acetate succinate (HPMCAS), polyvinylpyrrolidone (PVP), Eudragit E PO, polyvinylpyrrolidone vinyl acetate (PVPVA), hydroxyl propyl cellulose (HPC), polyacrylic acid (PAA), sodium carboxymethylcellulose (Na CMC), polyvinyl alcohol (PVA) 
and hydroxyethyl cellulose (HEC). As the miscibilities of felodipine with many polymers are well documented in the literature ${ }^{5,12,25}$, it is an excellent model drug to allow us to compare the TASC results with the existing literature data.

\section{Experimental Section}

\section{Materials}

The drug used in this study, felodipine form I, was purchased from Molekula (Dorest, UK) and confirmed as form I by PXRD, DSC and IR. Polyvinyl pyrrolidone vinyl acetate with a commercial name known as Plasdone ${ }^{\mathrm{TM}}$ S630 (PVPVA), hydroxyl propyl cellulose, commercially known as Klucel ${ }^{\mathrm{TM}}$ EF PHARM (HPC), hydroxypropyl methyl cellulose acetyl succinate, commercially known as AquaSolve ${ }^{\mathrm{TM}}$ (HPMCAS-MG grade), sodium carboxy methyl cellulose, commercially know as Aqualon $^{\mathrm{TM}}$ CMC 7L2P (Na CMC), polyvinyl pyrrolidone, commercially known as Plasdone ${ }^{\mathrm{TM}}$ K29-32 (PVP) and hydroxyethyl cellulose, commercially known as Natrosol ${ }^{\mathrm{TM}} 250$ L PHARM (HEC) were kindly supplied by Ashland Industries Europe GmbH (Schaffhausen, Switzerland). Polyacrylic acid (PAA) was ordered from Sigma-Aldrich (St. Louis, US). Eudragit ${ }^{\circledR}$ E PO (poly(butyl methacrylate-co-(2dimethylaminoethyl) methacrylate-comethyl methacrylate)) was kindly provided by Evonik Industries (Darmstadt, Germany). Polyvinyl alcohol (PVA) with 88\% hydrolysation was purchased from Acros Organics (New Jersey, USA). Soluplus ${ }^{\circledR}$ (polyvinyl caprolactampolyvinyl acetate-polyethylene glycol graft copolymer) was kindly supplied from BASF (Ludwigshafen, Germany). $\mathrm{NaCl}(\geq 99.0 \%$ ) was purchased from Thermo Fisher Scientific (Geel, Belgium). The solvents used for the polymer films preparation were dichloromethane anhydrous ( $\geq 99.8 \%)(\mathrm{DCM})$ and absolute ethanol. Both were purchased from Sigma-Aldrich (Gillingham, Dorset, UK). 


\section{Preparation of polymer coated glass substrates by spin coating}

Spin coated thin films of different polymers were prepared using Spincoat G3P-8 (Specialty Coating Systems, Indianapolis, US). Various polymer solutions were prepared and the details can be found in Supplementary Information Table S1. In all cases, 2-5 drops of the prepared solutions were dispensed to the top of a glass coverslip with a glass pipette. This was followed by continuous spinning using $2000 \mathrm{rpm}$ for 120 seconds to evaporate the solvent and form a uniform polymeric thin film on the coverslip. The volume of the solution dispensed was judged by through full coverage of the film on the surface of the slide, thus it varied with the viscosity and surface tension of each solution. The thickness of the pure polymeric films was measured after the preparation as described in Table S1 using electronic thickness gauge model ET-3 (West Lafayette, US) and expressed as the average \pm SD ( $\mathrm{n}=5$ ).

\section{Thermal Analysis by Structural Characterisation (TASC)}

TASC characterisation was performed using a TASC system composed of a Linkam MDSG600 heat-cool automated temperature controlling stage attached to a Linkam imaging station equipped with reflective LED light source and a 10X magnification lens (Linkam Scientific Instruments Ltd, Surry, UK). Felodipine particles used for analysis were selected within the range of $90-100 \mu \mathrm{m}$ by passing the felodipine powder through 100 and $90 \mu \mathrm{m}$ sieves for 5 minutes. Particles passing through 100- $\mu \mathrm{m}$ sieve and retained by $90-\mu \mathrm{m}$ sieve were collected and used for analysis. The particles were sprinkled on the substrate. High packing density that causes particle overlapping should be avoided to ensure the quality of the data acquisition. Characterisation was conducted using two experimental methodologies: heating only $\left(30-180{ }^{\circ} \mathrm{C}\right)$ and heating-isothermal (heating to above the melting and keeping isothermal for 15 minutes). Heating rates of $20{ }^{\circ} \mathrm{C} / \mathrm{min}$ were used for the TASC screening. In addition, analysis was also performed on solid dispersions loaded with $10-100 \% \mathrm{w} / \mathrm{w}$ 
felodipine in Soluplus with $10 \% \mathrm{w} / \mathrm{w}$ increments between consecutive loadings as a representative polymer/drug system to investigate the use of TASC to determine the maximum solubility of a drug in polymer.

For all TASC experiments, stacks of images of the sample were collected simultaneously with a rate of 1 frame $/{ }^{\circ} \mathrm{C}$ using a black background to restrict the analysis to the crystalline felodipine form I particles and reduce the noise to signal ratio. These acquired images were analyzed using TASC software and the changes in the appearance of felodipine particles during the different regimes were converted into normalized curves against temperature or time $^{24}$. Statistical analysis using one-way ANOVA was performed to understand the significance of the differences between the signals and the melting onsets of the samples. Statistical significance was accepted at a $p$ value $\leq 0.05$.

In order to investigate the best sampling method for the data analysis, ROI's were chosen either from the particle edge or the large central regions of the particles. It was found that large ROI's covering the central region gave more reproducible results. Therefore, all analyses were performed on five felodipine particles for each set of data using large ROIs.

\section{Thermogravimetric Analysis (TGA)}

TGA Q5000 (TA Instruments, Newcastle, USA) was used to study the thermal stability of felodipine and the polymers used in this work before the design of the TASC temperature programmes to eliminate any possibility of degradation during the screening process. A heating rate of $20^{\circ} \mathrm{C} / \mathrm{min}$ for the range $25-550{ }^{\circ} \mathrm{C}$ was used for estimating the degradation onset of the compounds. Two replicates were tested and Universal Analysis software was used to analyze the acquired data. 


\section{Differential Scanning Calorimetry (DSC)}

DSC was used to identify the thermal properties such as the melting and the glass transition temperatures of different raw materials. A Q-2000 MTDSC (TA Instruments, Newcastle, USA) equipped with a RC 90 cooling unit was utilized for the characterization of these materials. The instrument was calibrated prior to the sample characterization. At least three replicates of 2-3 $\mathrm{mg}$ of each sample were scanned at $20^{\circ} \mathrm{C} / \mathrm{min}$ heating rate using standard aluminum TA crimped pans (TA Instruments, Newcastle, USA). The use of $20^{\circ} \mathrm{C} / \mathrm{min}$ is to match the heating rate used in the corresponding TASC experiments for each sample for the purpose of comparison. Universal Analysis software was used to analyze the collected data.

\section{IR imaging}

In order to understand the miscibility and diffusivity of felodipine in the polymeric spin coated films and the possibility of drug-polymer interaction, drug particles on uncoated glass coverslips as a control, or spin coated polymer films (Eudragit E PO, PVPVA, Soluplus or HEC) representing miscible, partially miscible or immiscible binary systems respectively were heated at $20^{\circ} \mathrm{C} / \mathrm{min}$ from $30-140^{\circ} \mathrm{C}$ and then kept isothermal slightly above the melting point of the drug for 15 minutes to allow for the maximum possible interaction between felodipine and the polymeric films. The samples were then analysed using a Nicolet iN10MX infrared microscope (Thermo Fisher Scientific, Madison, WI, US) with $25 \mu \mathrm{m}$ spatial resolution in transmission mode using the coverslip glass as a reference. With standard $0.17 \mathrm{~mm}$ glass coverslips the useable spectral range was from 4000 to $1200 \mathrm{~cm}^{-1}$. IR maps were acquired with 64 scans at $8 \mathrm{~cm}^{-1}$ spectral resolution, and analysed using the Omnic Picta software (Thermo Fisher) 


\section{Stability studies for validating the miscibility screening results}

Solid dispersions of felodipine in Soluplus (as a representative of miscible) and PAA (as a representative of immiscible) binary blends with high and low drug loading were prepared using spin coating method. The samples were stored at room temperature and $75 \%$ relative humidity (RH) for 1 month. At different time intervals (after 1 day, 1 week, 2 weeks and 1 month), the samples were examined using a polarized light microscope (Leica DM LS2; Germany) for the presence of felodipine crystals in the solid dispersions in order to validate the miscibility of drug and polymer obtained by TASC screening method.

\section{Correlation data analysis}

The data collected from TASC analysis for pure felodipine particles with or without the presence of the different polymeric substrates were analysed using Microsoft Excel correlation data analysis.

\section{Results and discussion}

Standardization of the analysis of melting point depression using TASC

Felodipine form I crystals showed an extrapolated melting onset at $141.0 \pm 0.3{ }^{\circ} \mathrm{C}$ detected using DSC at $20{ }^{\circ} \mathrm{C} / \mathrm{min}$ (same scanning rate as the one used in TASC) and thermal degradation onset approximately at $180{ }^{\circ} \mathrm{C}$ detected using TGA (Supplementary Information Figure S1). This DSC detected melting point is close to the melting onset reported in the literature which is $143.8 \pm 0.2{ }^{\circ} \mathrm{C}{ }^{26}$. The thermal events detected by the DSC and TGA were used in the design of TASC temperature programs to avoid drug degradation. As using TASC for screening relies on the detection of the change at the onset of drug melting, it is firstly important to standardise the data analysis of the onset of a TASC curve. As seen in Figure $2 \mathrm{~A}$, the signal of the melting of felodipine crystals on a glass substrate at $20{ }^{\circ} \mathrm{C} / \mathrm{min}$ shows 
the increase in signal intensity indicating the onset of the melting. The onset can be either analysed by the direct extrapolation of the signals such as is used for DSC data analysis (performed manually) or by taking the $2^{\text {nd }}$ derivative of the whole signal (performed using Origin software). It can be seen that the $2^{\text {nd }}$ derivative method produces a clear peak indicating the onset temperature. Both data analysis methods show very similar results, with the melting onset of felodipine at $143.4 \pm 0.9{ }^{\circ} \mathrm{C}$ which is close to the DSC results and the literature value. As all the screening tests are performed using TASC in this study, the value of melting point quoted above was used as the standard to with which melting point depressions were compared. As seen in Figure 2B, once the drug particle was analysed on a polymer coated substrate there was more complex behaviour, which made the second derivative method less reliable. Therefore, the extrapolation method was selected and used as the data analysis method for all samples studied.

It is important to establish the effect of selection of the ROI on the accuracy and reproducibility of the results. Previously it has been reported that larger ROI's often give more reproducible results ${ }^{23}$. As shown in Figure 3 A-D, multiple drug particles were tested on Soluplus coated substrates, either the particle edges or the large central region of the particles were selected as the ROIs and analysed. When selecting large central areas of the drug particles, the signal is less noisy within the onset and melting region, resulting in a smaller standard deviation (SD) for the large ROI sampling (in the example of Figure 3 the average of the extrapolated melting onset $\pm \mathrm{SD}$ is $115.6 \pm 6.4^{\circ} \mathrm{C}$ and $114.4 \pm 1.5^{\circ} \mathrm{C}$ for of the edge and the large ROIs, respectively). The improvement in the reproducibility using large ROI may be attributed to the low level of the geometrical differences between the different large ROI areas. The variability in the change of the images on the edge regions is greater than the central region due to large variation in the thickness and shape of the edges. 
In addition to the selection of ROI, it is also important to establish the effect of polymer film thickness on the TASC responses. As seen in Figure 4, two sets of polymer-coated substrates with different coating thickness were used to test the melting of the crystalline felodipine particles that were placed on top. The thicknesses of the films were either $17.8 \pm 8.0 \mu \mathrm{m}$ (with $40 \% \mathrm{w} / \mathrm{w}$ Eudragit solution as the coating solution) or $1.6 \pm 1.3 \mu \mathrm{m}$ (with $20 \% \mathrm{w} / \mathrm{w}$ Eudragit E PO solution). The extrapolated onset of the depressed melting of the drug are $104.6 \pm 1.5^{\circ} \mathrm{C}$ for the thick and $102.1 \pm 3.4{ }^{\circ} \mathrm{C}$ for the thin film. The signals of the two sets of samples show no statistically significant difference $(\mathrm{P}>0.05)$. As the results demonstrate no statistically significance for the two extreme thicknesses that cover the full range of the film thickness used in this study, we are confident that the data reported in this study using different polymer films can be reliably compared for their difference in the miscibility with the model drug. Therefore whilst standardization of the film thickness would be ideal, it is in practice often extremely challenging to achieve and does not make a significant improvement in data.

\section{Miscibility screening using TASC}

TASC analysis was used to experimentally detect the onset of melting point depression of felodipine in the presence of polymers. As seen in Figure 5, the polymers led to different levels of depression of the melting of crystalline felodipine. The depressed melting points are summarized in Table 1. Based on the magnitude of depression of the onset of the drug melting, the polymers can be ranked in the order of Eudragit E PO $>$ Soluplus $=$ HPC $>$ PVPVA $>$ HPMCAS $>$ PVP K29/32 $>$ PAA $=$ HEC $=$ PVA $=$ Na CMC, with Eudragit E PO being most miscible with felodipine. The miscibility ranking by TASC with Eudragit E PO, Soluplus, PVPVA and HPMCAS agree well with literature data ${ }^{12,27,28}$. However, within the 
literature there is no direct comparison of these ten polymers. Therefore, the traditional method used for predicting the drug polymer miscibility using solubility parameters was used to compare with the TASC results.

The calculations of the solubility parameters of the drug in the polymers are detailed in the Supplementary information. The results alongside the TASC results are summarised in Table 1. The solubility parameter approach is widely used in the literature for estimating drugpolymer miscibility using a group contribution method ${ }^{29,30}$. The rule of thumb for ranking is that if the difference in the solubility parameter $(\Delta \delta)$ between the drug and the polymer is less than $7\left(\mathrm{MJ} / \mathrm{m}^{3}\right)^{1 / 2}$, the binary mixture is considered being miscible, while if the value of the $\Delta \delta$ is more than $10\left(\mathrm{MJ} / \mathrm{m}^{3}\right)^{1 / 2}$, this indicates immiscibility. Intermediate values for $\Delta \delta$ were considered as an indication of partial miscibility ${ }^{31-33}$. Based on this approach, felodipine is expected to have good miscibility with eight of the studied polymers: PAA, PVPVA, Eudragit E PO, HPC, Soluplus, HEC, HPMCAS and PVP K29/32. The drug is predicted to be partially miscible with $\mathrm{Na} \mathrm{CMC}$ and PVA as the $\Delta \delta$ between the drug and the polymers are between 7-10 $\left(\mathrm{MJ} / \mathrm{m}^{3}\right)^{1 / 2}$. Within these eight polymers, experimentally HEC and PAA show a statistically insignificant melting point depression of felodipine when tested using TASC, indicating poor miscibility. PVA was predicted to be partially miscible with felodipine as its $\Delta \delta$ values fall between $7-10\left(\mathrm{MJ} / \mathrm{m}^{3}\right)^{1 / 2}$ but the TASC results confirmed that this polymer is at the bottom of the miscibility ranking and showed no melting point depression.

\section{Post-melting polymer-drug mixing as another indication of miscibility}

Significant differences in the TASC curves at the post-melting temperature regions can be observed in Figure 5 when the drug particles were melted on different polymers. This post- 
melting region reflects the thermal process of the continuous mixing of the drug in the softened polymer. The post-melting behaviour of the drug in the polymer was further investigated to confirm the miscibility of the drug with the polymer. The temperature program used in this study was to heat the drug polymer system at $20{ }^{\circ} \mathrm{C} / \mathrm{min}$ to $150{ }^{\circ} \mathrm{C}$ and maintaining it isothermal for 15 minutes. The presence of a detectable event during the isothermal cycle slightly above the melting temperature is further indication of miscibility between the drug and the polymer, since an immiscible liquid will remain unchanged at the interface, but a miscible liquid will tend to spread and dissolve. The results of this screening were then converted into graphs of normalised values against time, which show the presence or absence of post-melting events. Figure 6 shows the heat-isothermal analysis for the pure felodipine form I on representative examples of polymeric substrates for miscible and immiscible drug-polymer blends. No polymer-drug melt-mixing event was detected for felodipine crystals above HEC, Na CMC, PVA and PAA polymeric substrates indicating no further events other than the pure melting of the drug. In contrast, the other polymers (PVPVA, Soluplus, HPC, Eudragit E PO, HPMCAS and PVP K29/32) which showed melting point depression of crystalline felodipine detected by TASC all show the presence of further events after the melting of the drug, as highlighted in Figure 6. The results of the heating-isotherm above the melting are closely associated with the melting point depression detected by TASC screening using the single heating cycle. This confirms that good miscibility between the polymer and drug should exhibit melting depression which is companied by further mixing of the molten drug in the polymer. The most miscible pair of drug-polymer combination is expected to show most substantial change of the curve during isothermal period. Using the simple correlation analysis, the melting and heating-isothermal curves of the pure drug on a glass substrate were compared with the curves of the first heating cycle and the heating-isotherm cycle of the drug analysed on polymer coated 
substrates. As shown in Figure 7, the most miscible polymers with felodipine, Eudragit EPO and Soluplus, exhibit much lower correlation with the heating-isothermal TASC data, indicating their clear miscibility advantage over other polymers.

\section{Confirming miscibility using IR imaging}

In order to further validate the screening method and confirm the interactions between the different polymers with felodipine, the samples were analyzed using IR imaging after TASC heat-isotherm screening. The analysis is based on mapping the distribution of drug and polymer. The wavenumber region of $3600-2800 \mathrm{~cm}^{-1}$ was used to identify the presence of both the drug and the polymer as they both have well-separated peaks within this region. The boundary of the molten felodipine drug particle without polymer is shown in Figure 8A. There is a sharp boundary shown in light blue between the molten drug and the substrate. This is also apparent in Figure 8I in which HEC was the underlining polymer with no detectable melting point depression. In contrast, in Figure $8 \mathrm{C}$ and $\mathrm{E}$ where the substrates were coated with Eudragit E PO and Soluplus the boundaries are diffused indicating the diffusion of the molten drug into the polymer. Caution is needed for interpreting the contour map as the colors in the contour maps are indicative of the presence of the drug. Although the gradient is scaled to the height of the felodipine NH band (see the absorbance scales of the spectra graphs shown in Figure $8 \mathrm{~B}, 8 \mathrm{D}, 8 \mathrm{~F}, 8 \mathrm{H}, 8 \mathrm{~J})$, the colours are not a linear measure of the concentration of the drug but indicate spatial zones through the 3-dimensional droplet and the corresponding colour-coded spectra indicate the composition in those areas. As shown in Figure 8G, despite PVPVA being measured to be miscible with felodipine, the boundary is still relatively sharp. This could be due to a range of factors including surface tension, viscosity and diffusivity of the drug in the underlining polymer. Therefore careful analysis of the spectra is also required. 
As shown in Figure 8B, without any polymeric substrate, felodipine was converted completely from form I into its amorphous form after melting, as indicated by the uniform blue shift in its $\mathrm{NH}$ stretching mode from 3372 to $3339 \mathrm{~cm}^{-1}$ due to the stronger intermolecular hydrogen bonding between its molecules in the amorphous form as reported in the literature ${ }^{26,34-36}$. In the spectra of felodipine on Eudragit E PO (Figure 8D), the $\mathrm{NH}$ stretching band of the drug revealed an increasing shift to higher wavenumbers as the drug diffuses away from the center of the molten drug particle. This indicates that the hydrogen bonds became weaker as the drug dissolved in the polymer. The spectra of Figure $8 \mathrm{~F}$ and $\mathrm{H}$ show more complicated behaviour. Shoulder peaks appear at a lower wavenumber and increase in intensity with distance from the center of the drug particle. This is indicative of stronger hydrogen bond formation between the drug and the Soluplus and PVPVA. No shift or shoulder peak of the NH band was observed for felodipine on HEC film indicating no diffusion into the HEC film at all (Figure 8J). The overall results of IR imaging were consistent with the data collected from TASC screening. In both methods the miscible drug polymer pairs showed interaction (melting point depression, diffusion in the polymer film), however the different extent and direction of the shift in the $\mathrm{NH}$ bands demonstrated that the precise nature of these interactions depends on the chemical structures.

\section{TASC screening results compared to real-time stability studies}

Physical instability of solid dispersions can be caused by either moisture uptake (which plasticize the material) and/or elevated environmental temperature. In simple terms, both of these conditions effectively reduce the gap between the $T_{g}$ of the samples and the storage temperature, increasing the molecular mobility of the samples. In general, a formulation containing a polymeric excipient with good miscibility with the drug and an appropriate drug 
loading (below the saturated solubility of drug in the polymer) often can provide a stabilizing effect and minimize drug recrystallization under stressed conditions, whereas poor polymerdrug miscibility often leads to the rapid development of phase separation and drug crystallization $^{5-8,21,27,35}$. In order to test the validity of the TASC screening of polymer-drug miscibility, real-time stability of binary solid dispersions (10-90\% drug loading) of felodipine with one miscible (felodipine-Soluplus) and one immiscible polymer (felodipine-PAA) were prepared as solid dispersion films. The samples were aged at room temperature and $75 \% \mathrm{RH}$. Such high relative humidity is often employed in pharmaceutical stability testing to accelerate instability. However it should be highlighted here that the full effects of moisture uptake occurring with storage under high humidity are complex and can strongly perturb the thermodynamic equilibrium and hence physical stability of these systems. Here we are not claiming any correlation between the TASC results and the physical stability of the solid dispersions, but seeking to understand if a relationship exists between the stabilization effect of the polymers and the prediction of miscibility measured by TASC. Felodipine in Soluplus is expected to be more a miscible binary blend than felodipine-PAA based on TASC screening. Pure felodipine began recrystallising immediately after spin coating and almost completely crystallised after 1 day of storage as seen in Figure 9A. The felodipine-Soluplus formulations with up to $50 \%$ drug loading were free of any crystallisation after 1 month, while the higher loadings revealed the presence of crystals as shown in Figure 9B-D. This may be due to the drug loading exceeding the equilibrium solubility of the drug in Soluplus under the aging condition. However this needs further investigation as crystallization may be affected by kinetic factors. In contrast felodipine PAA solid dispersions, after 1 month of aging showed the presence of felodipine crystals, indicating the poor miscibility between the two components as seen in Figure $9 \mathrm{E}$ and F. These results demonstrate that there is a correlation between the miscibility prediction by TASC and the physical stability of the 
samples. However further investigation is required to understand the molecular basis of the stabilization mechanism which is outside the scope of this study.

\section{Conclusion}

This study described the development of a rapid drug-polymer miscibility screening method based on TASC which allows rapid elimination of unsuitable candidates of excipients. The new thermal imaging based TASC screening method is $20-40$ times faster, in terms of screening speed, than the conventional DSC method for melting point depression detection. In addition there is an increase in sensitivity of detection with the use of only $1 / 1000^{\text {th }}$ of amount of the testing materials used in conventional DSC. The method was able to screen the miscibility of the model drug, felodipine, with ten pharmaceutical polymers using the magnitude of melting depression of felodipine in the presence of the polymers. Post-melting drug-polymer mixing studies provide valuable and unique information of the mixing between the molten drug and the softened polymer, which further confirms the miscibility. IR imaging and long-term stability studies provide further validation of the screening results obtained by TASC method. The results of this study demonstrated the clear advantages (such as being fast and inexpensive and user-friendly) of using this new thermal imaging tool as a screening method of drug-polymer miscibility during the preformulation phase of pharmaceutical product development and its potential of being further developed into a high throughput screening method.

\section{Acknowledgement}

This project has received funding from the Interreg 2 Seas programme 2014-2020 co-funded by the European Regional Development Fund under subsidy contract 2S01-059_IMODE. We would also like to acknowledge BBSRC, as QIB receives strategic funding from the BBSRC. 


\section{Reference:}

1. Liu, J.; Xiao, Y.; Allen, C. Polymer-drug compatibility: A guide to the development of delivery systems for the anticancer agent, ellipticine. Journal of Pharmaceutical Sciences 2004, 93, (1), 132-143.

2. Sun, Y.; Tao, J.; Zhang, G. G. Z.; Yu, L. Solubilities of Crystalline Drugs in Polymers: An Improved Analytical Method and Comparison of Solubilities of Indomethacin and Nifedipine in PVP, PVP/VA, and PVAc. Journal of Pharmaceutical Sciences 2010, 99, (9), 4023-4031.

3. Tian, B.; Wang, X.; Zhang, Y.; Zhang, K.; Zhang, Y.; Tang, X. Theoretical Prediction of a Phase Diagram for Solid Dispersions. Pharmaceutical Research 2015, 32, (3), 840-851.

4. Pawar, J.; Suryawanshi, D.; Moravkar, K.; Aware, R.; Shetty, V.; Maniruzzaman, M.; Amin, P. Study the influence of formulation process parameters on solubility and dissolution enhancement of efavirenz solid solutions prepared by hot-melt extrusion: a QbD methodology. Drug Delivery and Translational Research 2018.

5. Marsac, P. J.; Shamblin, S. L.; Taylor, L. S. Theoretical and Practical Approaches for Prediction of Drug-Polymer Miscibility and Solubility. Pharmaceutical Research 2006, 23, (10), 2417.

6. Marsac, P. J.; Li, T.; Taylor, L. S. Estimation of Drug-Polymer Miscibility and Solubility in Amorphous Solid Dispersions Using Experimentally Determined Interaction Parameters. Pharmaceutical Research 2008, 26, (1), 139.

7. Meng, F.; Dave, V.; Chauhan, H. Qualitative and quantitative methods to determine miscibility in amorphous drug-polymer systems. European Journal of Pharmaceutical Sciences 2015, 77, 106-111.

8. Meng, F.; Trivino, A.; Prasad, D.; Chauhan, H. Investigation and correlation of drug polymer miscibility and molecular interactions by various approaches for the preparation of amorphous solid dispersions. European Journal of Pharmaceutical Sciences 2015, 71, 12-24.

9. Anderson, B. D. Predicting Solubility/Miscibility in Amorphous Dispersions: It Is Time to Move Beyond Regular Solution Theories. Journal of Pharmaceutical Sciences 2018, 107, (1), 24-33.

10. Djuris, J.; Nikolakakis, I.; Ibric, S.; Djuric, Z.; Kachrimanis, K. Preparation of carbamazepine-Soluplus ${ }^{\circledR}$ solid dispersions by hot-melt extrusion, and prediction of drug-polymer miscibility by thermodynamic model fitting. European Journal of Pharmaceutics and Biopharmaceutics 2013, 84, (1), 228-237.

11. Pina Maria, F.; Zhao, M.; Pinto João, F.; Sousa João, J.; Craig Duncan, Q. M. The Influence of Drug Physical State on the Dissolution Enhancement of Solid Dispersions Prepared Via Hot-Melt 
Extrusion: A Case Study Using Olanzapine. Journal of Pharmaceutical Sciences 2014, 103, (4), 12141223.

12. Tian, Y.; Booth, J.; Meehan, E.; Jones, D. S.; Li, S.; Andrews, G. P. Construction of DrugPolymer Thermodynamic Phase Diagrams Using Flory-Huggins Interaction Theory: Identifying the Relevance of Temperature and Drug Weight Fraction to Phase Separation within Solid Dispersions. Molecular Pharmaceutics 2013, 10, (1), 236-248.

13. Knopp, M. M.; Tajber, L.; Tian, Y.; Olesen, N. E.; Jones, D. S.; Kozyra, A.; Löbmann, K.; Paluch, K.; Brennan, C. M.; Holm, R.; Healy, A. M.; Andrews, G. P.; Rades, T. Comparative Study of Different Methods for the Prediction of Drug-Polymer Solubility. Molecular Pharmaceutics 2015, 12, (9), 3408-3419.

14. Rask, M. B.; Knopp, M. M.; Olesen, N. E.; Holm, R.; Rades, T. Comparison of two DSCbased methods to predict drug-polymer solubility. International Journal of Pharmaceutics 2018, 540, (1), 98-105.

15. Donnelly, C.; Tian, Y.; Potter, C.; Jones, D. S.; Andrews, G. P. Probing the Effects of Experimental Conditions on the Character of Drug-Polymer Phase Diagrams Constructed Using Flory-Huggins Theory. Pharmaceutical Research 2015, 32, (1), 167-179.

16. Altamimi, M. A.; Neau, S. H. Use of the Flory-Huggins theory to predict the solubility of nifedipine and sulfamethoxazole in the triblock, graft copolymer Soluplus. Drug Development and Industrial Pharmacy 2016, 42, (3), 446-455.

17. Tambasco, M.; Lipson, J. E. G.; Higgins, J. S. Blend Miscibility and the Flory-Huggins Interaction Parameter: A Critical Examination. Macromolecules 2006, 39, (14), 4860-4868.

18. Lin, S.-Y.; Lee, C.-J.; Lin, Y.-Y. Drug-polymer interaction affecting the mechanical properties, adhesion strength and release kinetics of piroxicam-loaded Eudragit E films plasticized with different plasticizers. Journal of Controlled Release 1995, 33, (3), 375-381.

19. Nair, R.; Nyamweya, N.; Gönen, S.; Martínez-Miranda, L. J.; Hoag, S. W. Influence of various drugs on the glass transition temperature of poly(vinylpyrrolidone): a thermodynamic and spectroscopic investigation. International Journal of Pharmaceutics 2001, 225, (1), 83-96.

20. Puttipipatkhachorn, S.; Nunthanid, J.; Yamamoto, K.; Peck, G. E. Drug physical state and drug-polymer interaction on drug release from chitosan matrix films. Journal of Controlled Release 2001, 75, (1), 143-153.

21. Sibik, J.; Löbmann, K.; Rades, T.; Zeitler, J. A. Predicting Crystallization of Amorphous Drugs with Terahertz Spectroscopy. Molecular Pharmaceutics 2015, 12, (8), 3062-3068.

22. Luebbert, C.; Klanke, C.; Sadowski, G. Investigating phase separation in amorphous solid dispersions via Raman mapping. International Journal of Pharmaceutics 2018, 535, (1), 245-252.

23. Reading, M.; Qi, S.; Alhijjaj, M., Local Thermal Analysis by Structural Characterization (TASC). In Thermal Physics and Thermal Analysis: From Macro to Micro, Highlighting Thermodynamics, Kinetics and Nanomaterials, Šesták, J.; Hubík, P.; Mareš, J. J., Eds. Springer International Publishing: Cham, 2017; pp 1-10.

24. Alhijjaj, M.; Reading, M.; Belton, P.; Qi, S. Thermal Analysis by Structural Characterization as a Method for Assessing Heterogeneity in Complex Solid Pharmaceutical Dosage Forms. Analytical Chemistry 2015, 87, (21), 10848-10855.

25. Alhijjaj, M.; Bouman, J.; Wellner, N.; Belton, P.; Qi, S. Creating Drug Solubilization Compartments via Phase Separation in Multicomponent Buccal Patches Prepared by Direct Hot Melt Extrusion-Injection Molding. Molecular Pharmaceutics 2015, 12, (12), 4349-4362.

26. Surov, A. O.; Solanko, K. A.; Bond, A. D.; Perlovich, G. L.; Bauer-Brandl, A. Crystallization and Polymorphism of Felodipine. Crystal Growth \& Design 2012, 12, (8), 4022-4030.

27. Song, Y.; Wang, L.; Yang, P.; Wenslow, R. M.; Tan, B.; Zhang, H.; Deng, Z. Physicochemical Characterization of Felodipine-Kollidon VA64 Amorphous Solid Dispersions Prepared by Hot-Melt Extrusion. Journal of Pharmaceutical Sciences 2013, 102, (6), 1915-1923.

28. Nollenberger, K.; Gryczke, A.; Meier, C.; Dressman, J.; Schmidt, M. U.; Brühne, S. Pair distribution function $\mathrm{X}$-ray analysis explains dissolution characteristics of felodipine melt extrusion products. Journal of Pharmaceutical Sciences 2009, 98, (4), 1476-1486. 
29. Forster, A.; Hempenstall, J.; Tucker, I.; Rades, T. Selection of excipients for melt extrusion with two poorly water-soluble drugs by solubility parameter calculation and thermal analysis. International Journal of Pharmaceutics 2001, 226, (1), 147-161.

30. Greenhalgh, D. J.; Williams, A. C.; Timmins, P.; York, P. Solubility parameters as predictors of miscibility in solid dispersions. Journal of Pharmaceutical Sciences 1999, 88, (11), 1182-1190.

31. Greenhalgh, D. J.; Williams, A. C.; Timmins, P.; York, P. Solubility parameters as predictors of miscibility in solid dispersions. J Pharm Sci 1999, 88, (11), 1182-90.

32. Kitak, T.; Dumičić, A.; Planinšek, O.; Šibanc, R.; Srčič, S. Determination of Solubility Parameters of Ibuprofen and Ibuprofen Lysinate. Molecules 2015, 20, (12), 19777.

33. Alhijjaj, M.; Belton, P.; Qi, S. An investigation into the use of polymer blends to improve the printability of and regulate drug release from pharmaceutical solid dispersions prepared via fused deposition modeling (FDM) 3D printing. European Journal of Pharmaceutics and Biopharmaceutics 2016, 108, 111-125.

34. Srčič, S.; Kerč, J.; Urleb, U.; Zupančič, I.; Lahajnar, G.; Kofler, B.; Šmid-Korbar, J. Investigation of felodipine polymorphism and its glassy state. International Journal of Pharmaceutics 1992, 87, (1), 1-10.

35. Konno, H.; Taylor, L. S. Influence of different polymers on the crystallization tendency of molecularly dispersed amorphous felodipine. J Pharm Sci 2006, 95, (12), 2692-705.

36. Tang, X. C.; Pikal, M. J.; Taylor, L. S. A Spectroscopic Investigation of Hydrogen Bond Patterns in Crystalline and Amorphous Phases in Dihydropyridine Calcium Channel Blockers. Pharmaceutical Research 2002, 19, (4), 477-483. 
Table 1. Solubility parameter values, thermal transitions (melting, glass transition and the measured depression in melting) with different methods of ranking for the compounds used in this study (the measurements were performed on 5 or more particles).

\begin{tabular}{|l|c|c|c|c|c|}
\hline \multicolumn{1}{|c|}{ Compound } & $\delta\left(\mathrm{MJ} / \mathrm{m}^{3}\right)^{1 / 2}$ & $\begin{array}{c}\Delta \delta \\
\left(\mathrm{MJ} / \mathrm{m}^{3}\right)^{1 / 2}\end{array}$ & $\begin{array}{c}\mathrm{TASC} \mathrm{T}_{\mathrm{m}}\left({ }^{\circ} \mathrm{C}\right) \\
(\mathrm{n}=5)\end{array}$ & $\begin{array}{c}\Delta \delta \\
\text { ranking }\end{array}$ & $\begin{array}{c}\text { TASC T }_{\mathrm{m}} \text { depression } \\
\text { ranking }\end{array}$ \\
\hline Eudragit E PO & 18.7 & 2.1 & $102.1 \pm 3.4$ & 5 & 1 \\
\hline Soluplus & 21.6 & 0.8 & $117.0 \pm 3.6$ & 4 & 2 \\
\hline HPC & 23.6 & 2.8 & $118.1 \pm 4.1$ & 6 & 2 \\
\hline PVPVA & 20.1 & 0.7 & $128.2 \pm 2.7$ & 3 & 4 \\
\hline HPMCAS & 21.1 & 0.3 & $131.3 \pm 2.3$ & 2 & 5 \\
\hline PVP K29/32 & 20.7 & 0.1 & $140.8 \pm 1.7$ & 1 & 6 \\
\hline PAA & 20.5 & 0.3 & $142.0 \pm 0.9$ & 2 & 6 \\
\hline HEC & 25.8 & 5.0 & $142.8 \pm 1.3$ & 7 & 6 \\
\hline PVA & 29.7 & 8.9 & $143.6 \pm 1.2$ & 9 & 6 \\
\hline Na CMC & 27.9 & 7.1 & $144.2 \pm 1.3$ & 8 & -- \\
\hline Felodipine & 20.8 & --- & $143.4 \pm 0.9$ & --- & 4 \\
\hline
\end{tabular}


Figure 1. Illustration of the TASC based drug-polymer miscibility screening method

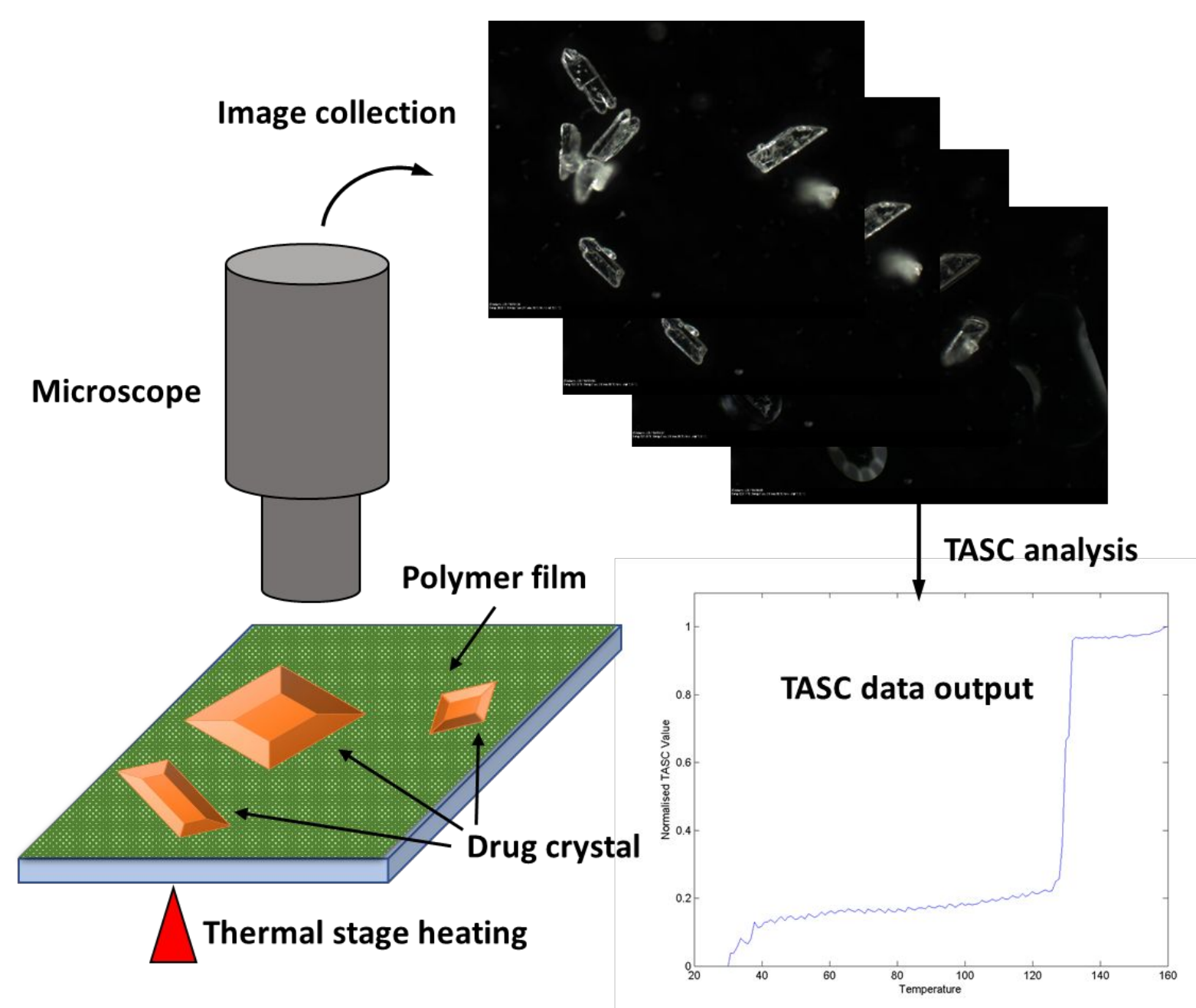


Figure 2: Method used to assign the melting point of felodipine using normalised TASC and the $2^{\text {nd }}$ derivative of the normalised TASC value. A) Pure felodipine form I TASC analysis and B) is the depressed melting point of the drug crystals due to the presence of Eudragit $\mathrm{E}$ PO film
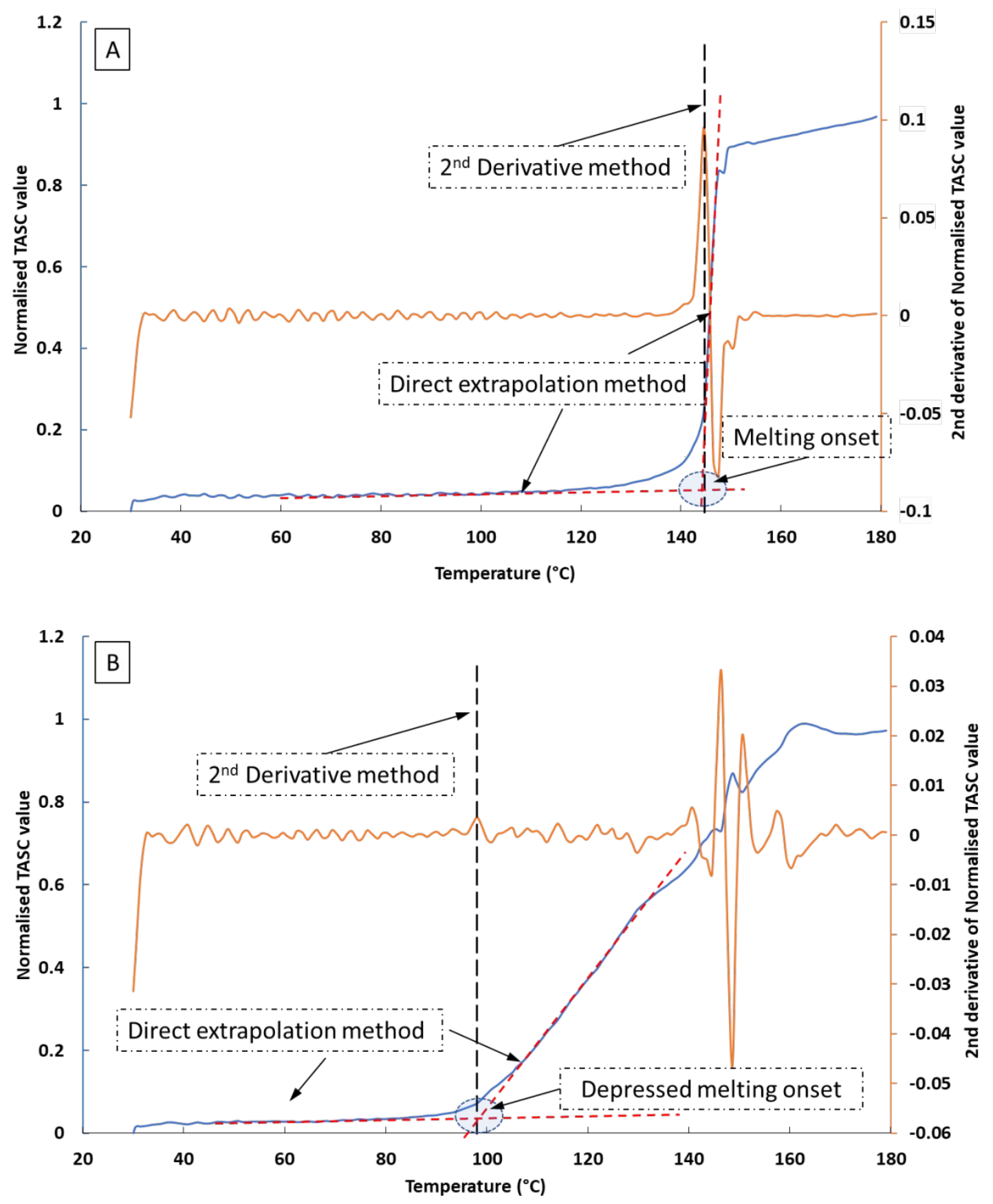
Figure 3: Reproducibility of microscopic and TASC analysis of felodipine crystalline particles on Soluplus film using heat ramp at $20^{\circ} \mathrm{C} / \mathrm{min}$ integrated using (A and B) the edge and $(\mathrm{C}$ and $\mathrm{D})$ the large central regions of the particle as the ROIs
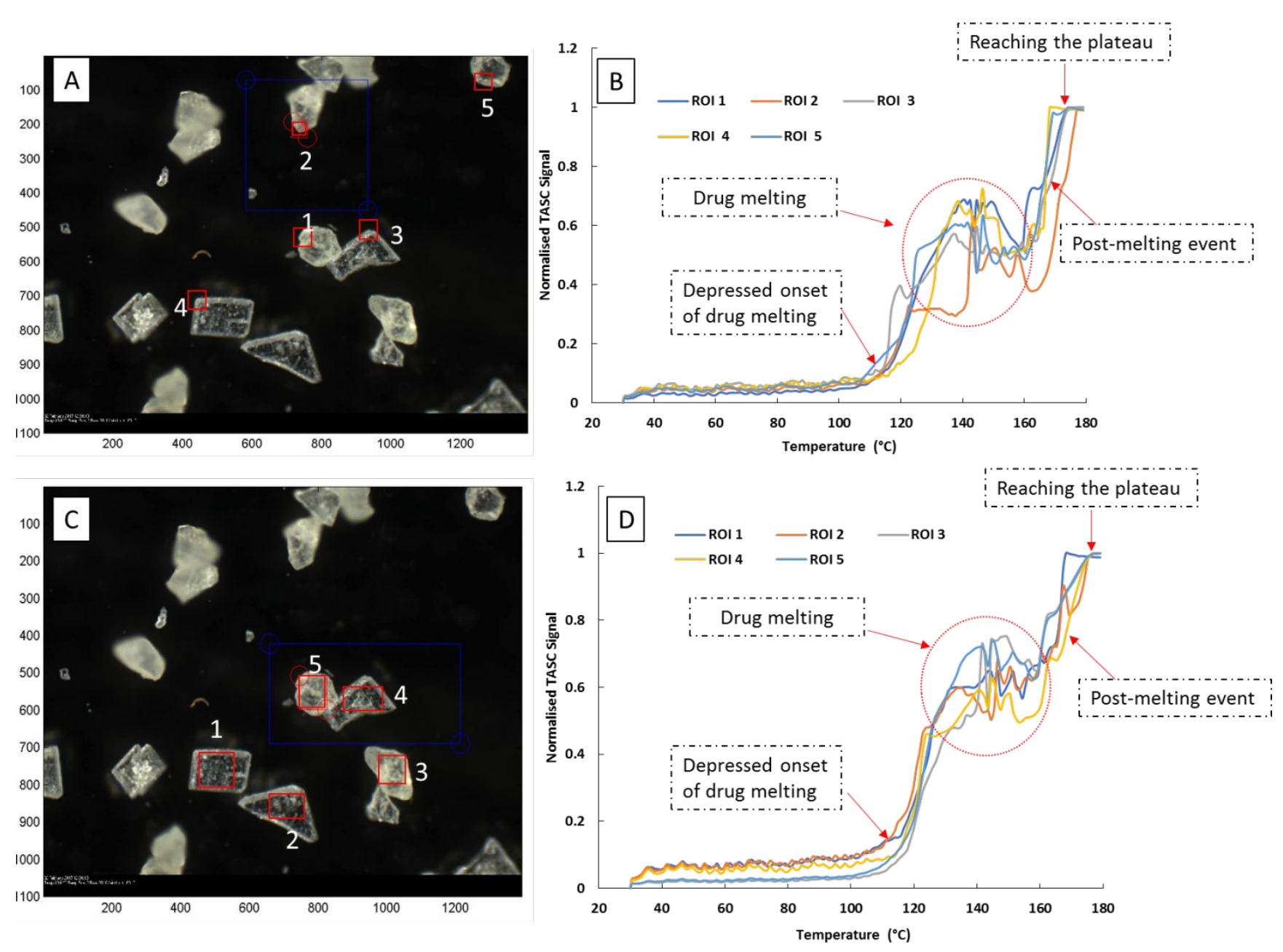
Figure 4. TASC signals of crystalline felodipine particles melted on the surfaces of Eudragit EPO coated substrates with either $1.6 \pm 1.3 \mu \mathrm{m}$ or $17.8 \pm 8.0 \mu \mathrm{m}$ thickness $(\mathrm{n}=5)$.

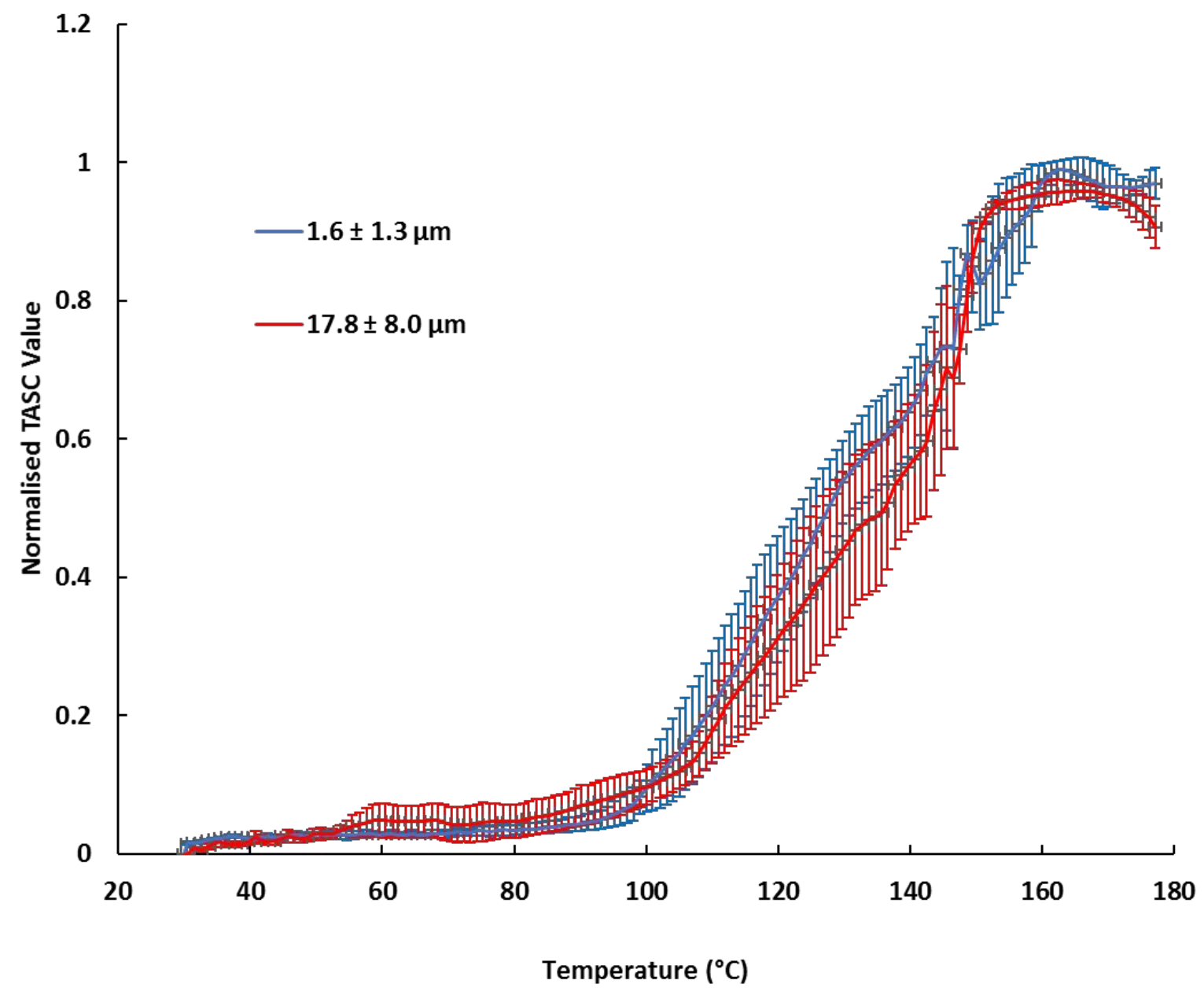


Figure 5. Melting point depression of felodipine form I particles caused by different polymeric spin coated substrates detected by TASC analysis using $20{ }^{\circ} \mathrm{C} / \mathrm{min}$ and large central regions of the particles as the ROI's; A) felodipine-Eudragit E PO, B) felodipineSoluplus, C) felodipine- PVPVA, d) felodipine- HPMCAS E) felodipine- Na CMC and F) felodipine-PAA
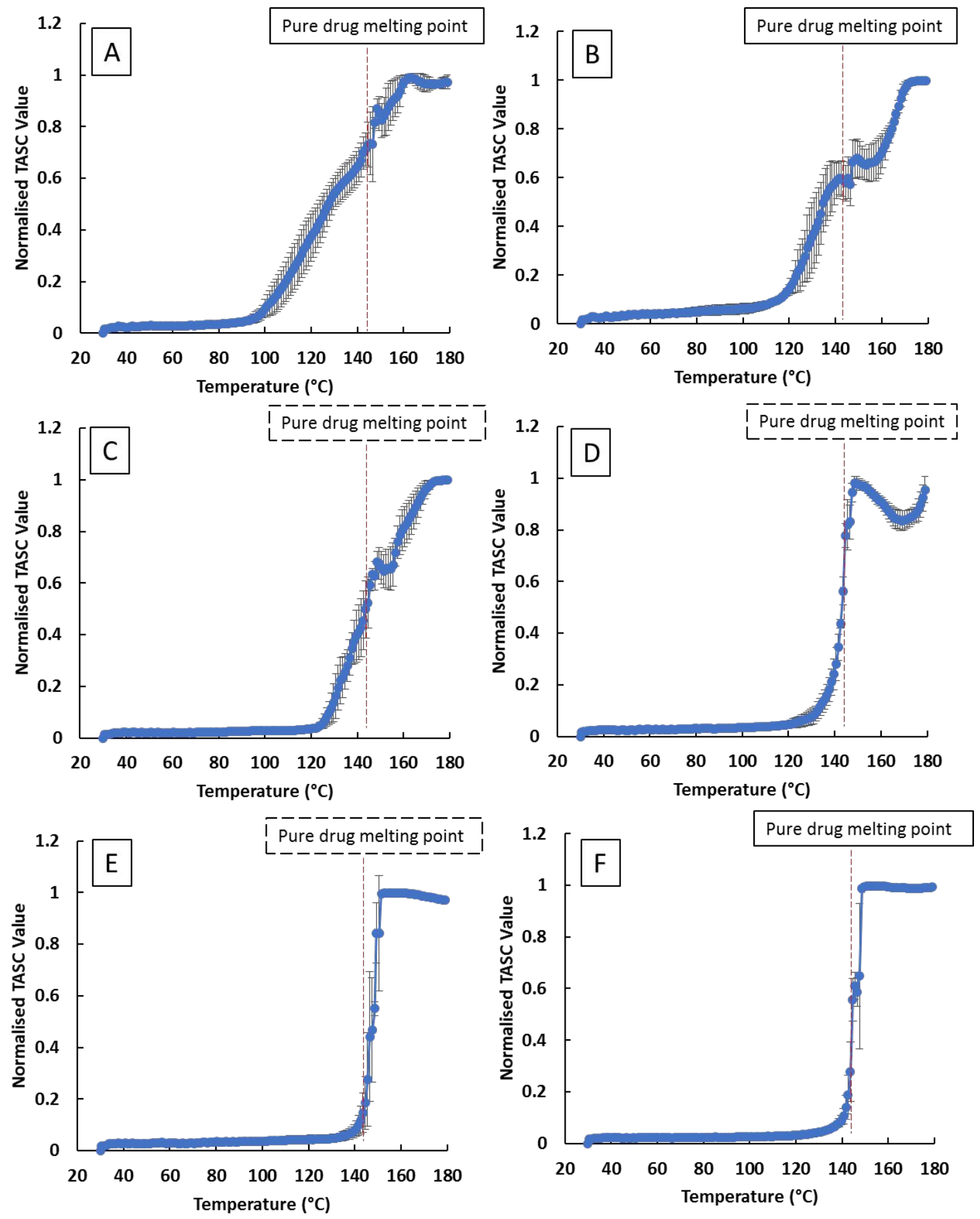
Figure 6. Post-melting drug-polymer mixing behaviour of felodipine form I particles caused by different polymeric spin coated substrates detected by TASC analysis using $20{ }^{\circ} \mathrm{C} / \mathrm{min}$ from $30-150{ }^{\circ} \mathrm{C}$ and then keeping isothermal for 900 seconds above the melting at $150{ }^{\circ} \mathrm{C}$; A) felodipine-PVPVA, B) felodipine-Soluplus, C) felodipine- HEC and D) felodipine- PVA
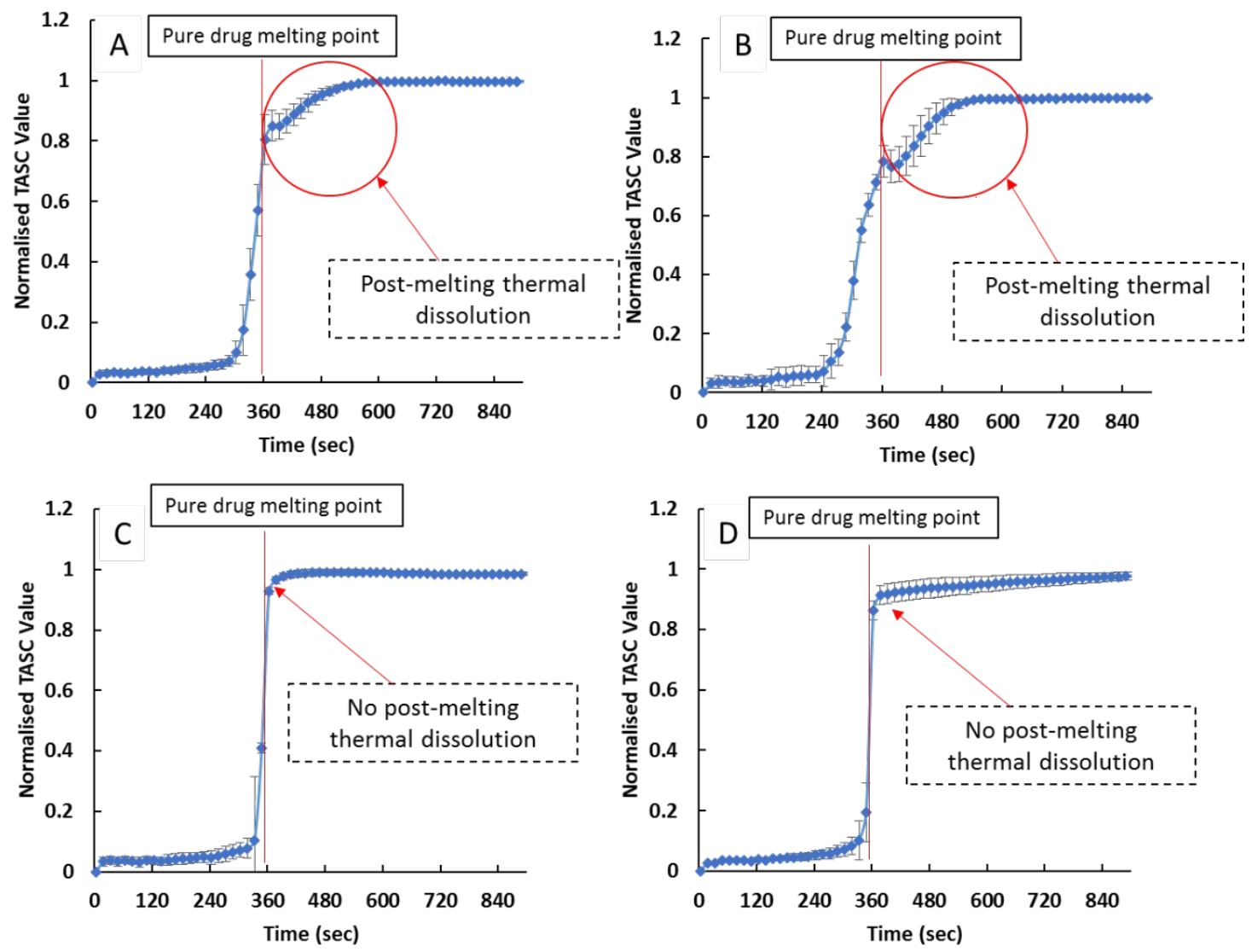
Figure 7. Plot of correlation coefficient of the entire normalised TASC signal for analysis felodipine form I particles on glass substrate with felodipine form I particle on different polymers during heating cycle (HC) and heating-isothermal cycle (HIC)

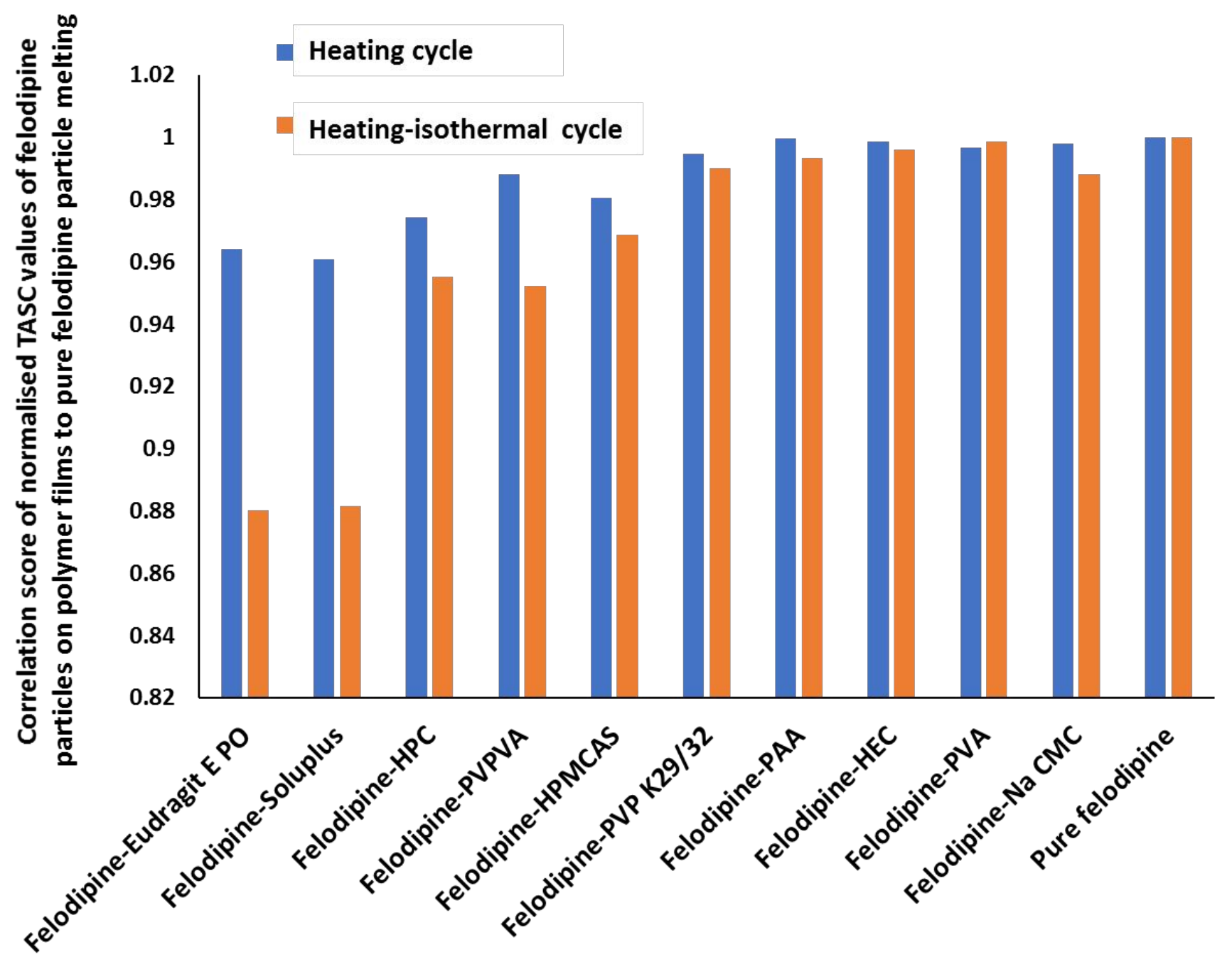


Figure 8. Figure 8. 2D IR images and spectra of representative felodipine particles on polymeric substrates of miscible and immiscible blends; A and B: molten felodipine in amorphous form on a glass coverslip; C and D: molten felodipine over Eudragit E PO film; E and F: molten felodipine over Soluplus film; $G$ and $H$ : molten felodipine over PVPVA film and I and J: molten felodipine over HEC film. The colour scale (blue-red) indicates the height of the felodipine $\mathrm{NH}$ band at $3339 \mathrm{~cm}^{-1}$ (marked with the dotted line) in each particle. The scale bars are $0.1 \mathrm{~mm}$. Spectra are extracted from line profiles across the particles and coloured according to the map (red spectra represent the centre of molten felodipine particle, the blue spectra represent the surrounding polymer film or glass in case of pure felodipine and the other spectra represent the middle zones). 

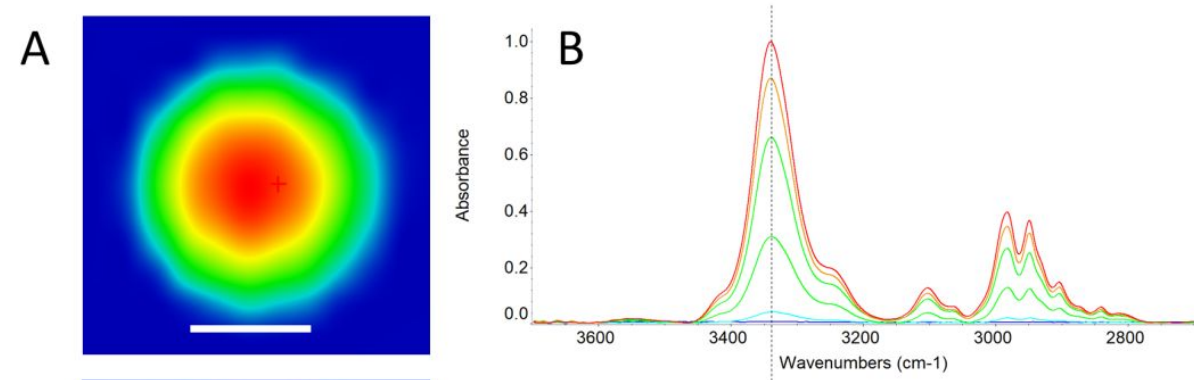

C
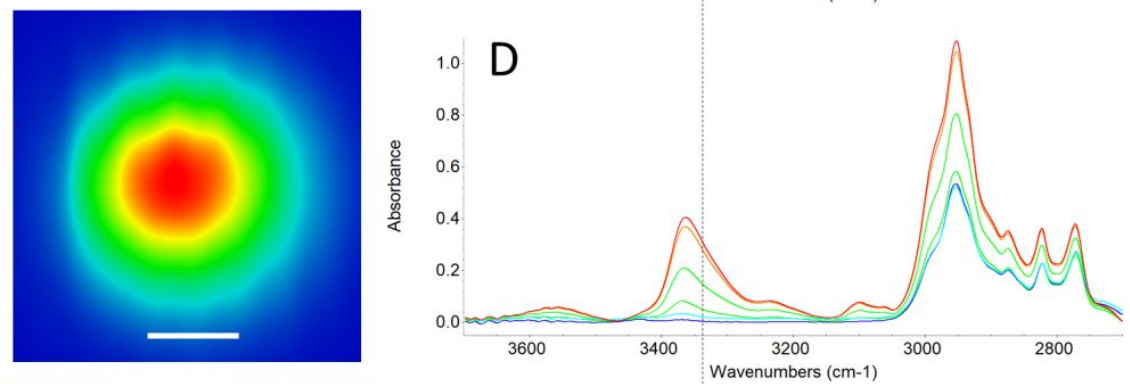

E
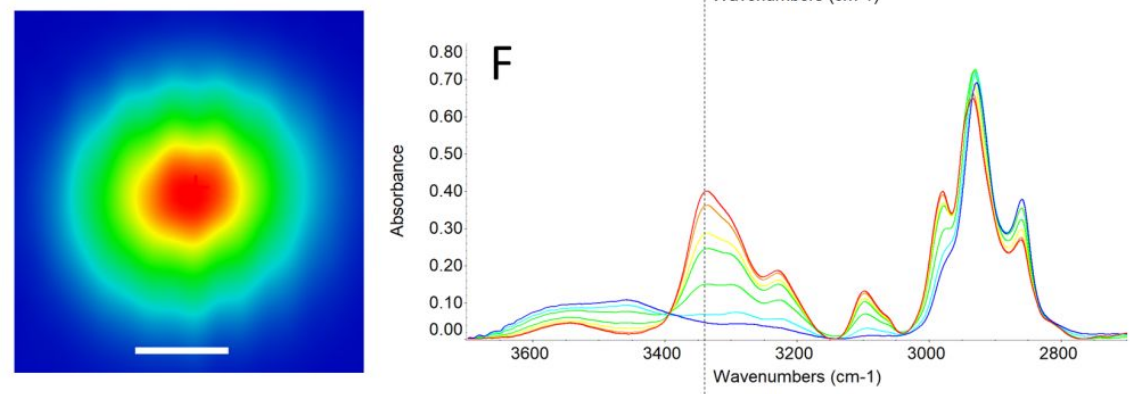

G
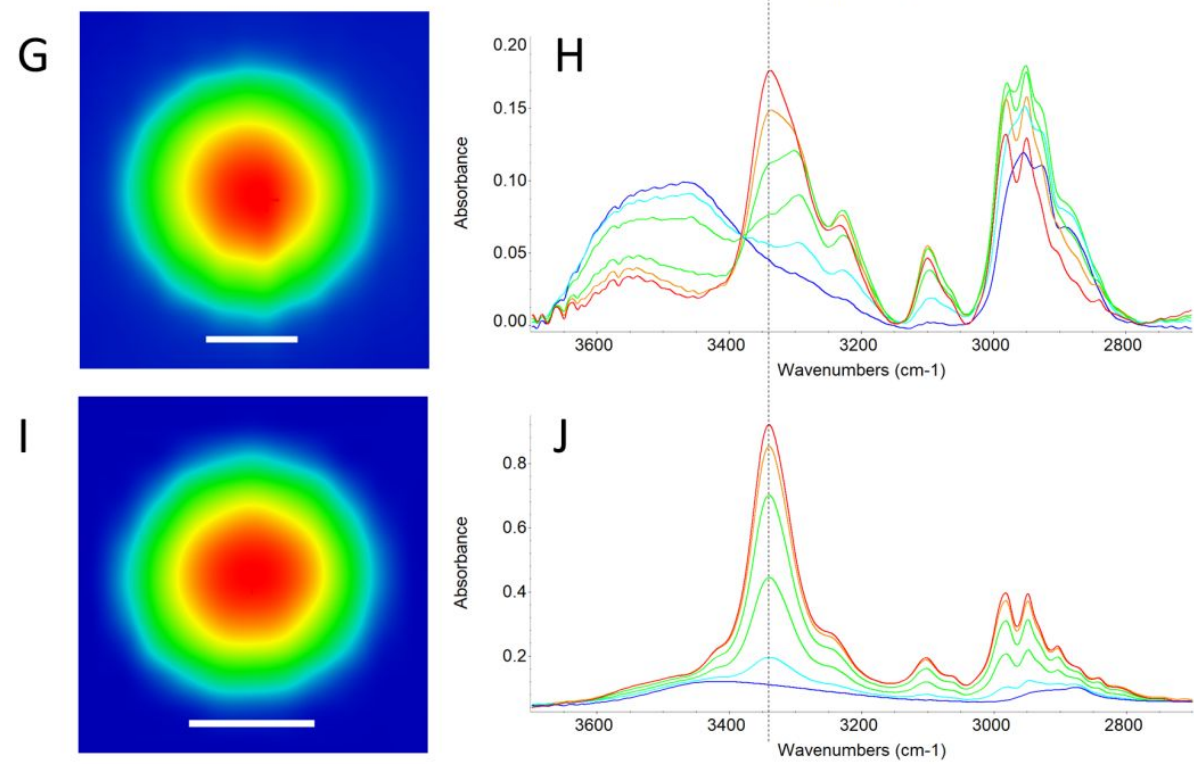

50

51

52

53

54

55

56 
Figure 9. Real-time stability study of felodipine solid dispersions in Soluplus and PAA at room temperature and 75\% relative humidity; A) pure felodipine recrystallised after 1 day, B) $50 \% \mathrm{~W} / \mathrm{W}$ felodipine in Soluplus after 1 month; C) 60\% W/W felodipine in Soluplus after 1 month; D) $90 \% \mathrm{~W} / \mathrm{W}$ felodipine in Soluplus after 1 month; E) $20 \% \mathrm{~W} / \mathrm{W}$ felodipine in PAA after 1 month and F) 90\% W/W felodipine in PAA after 1 month.
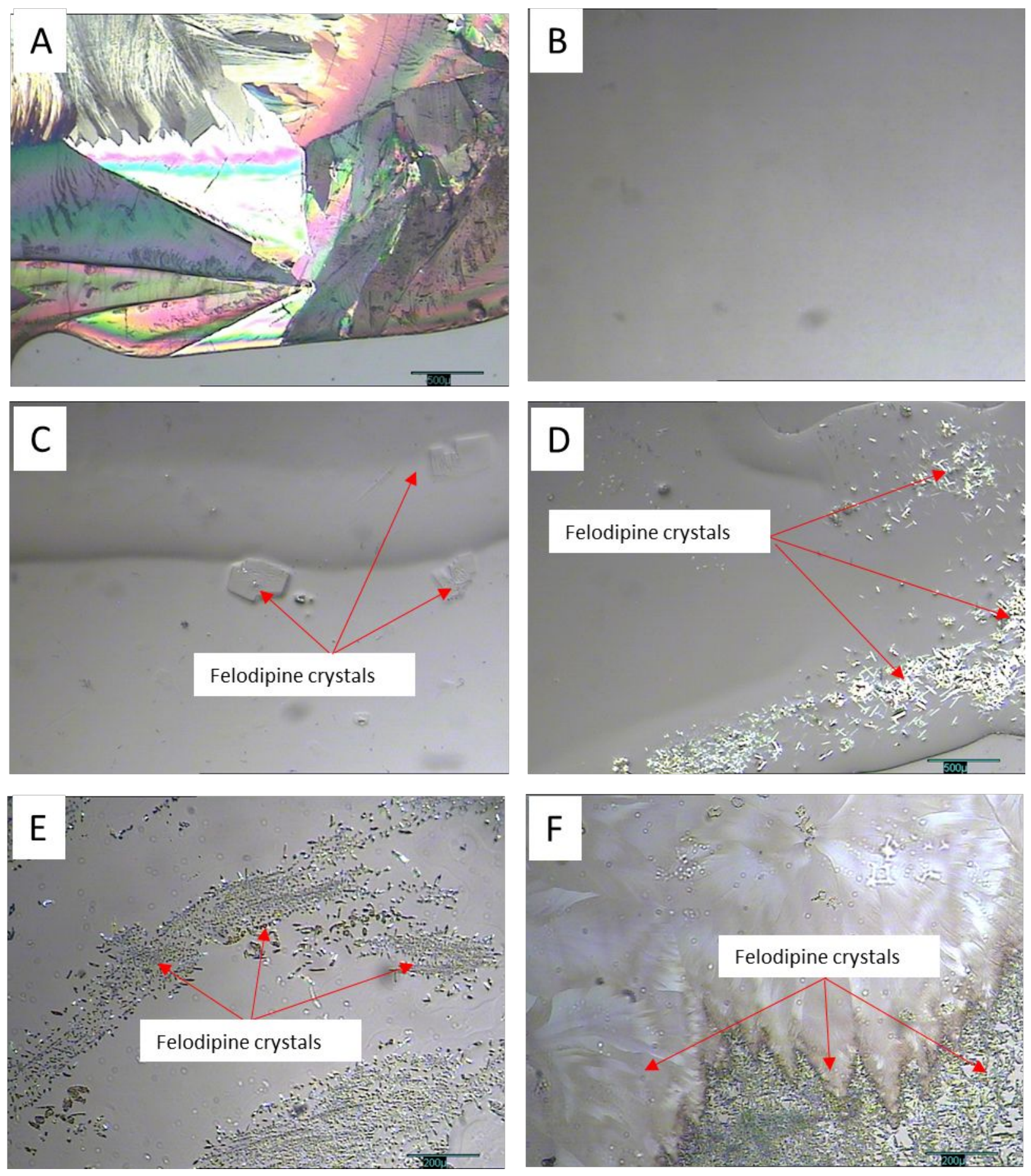


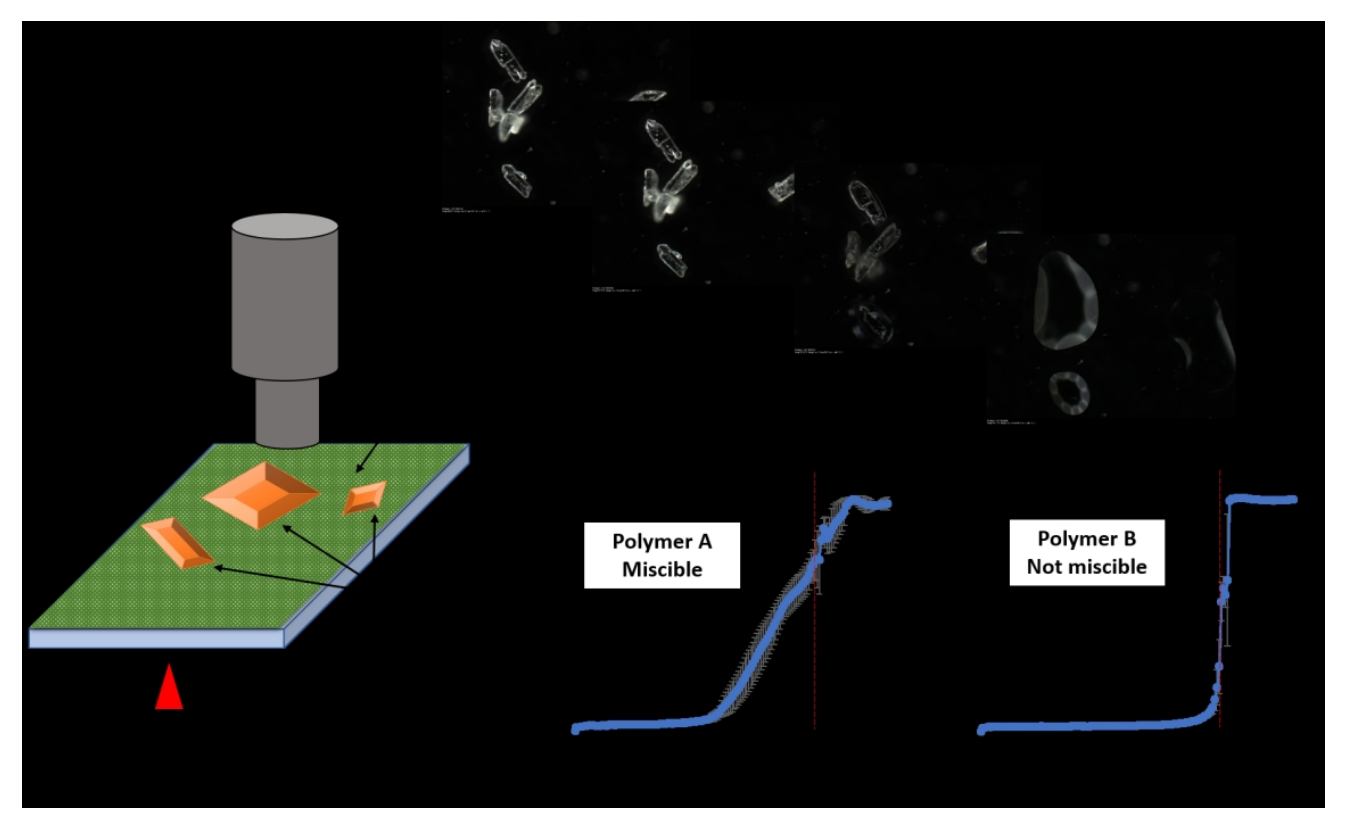

$314 \times 189 \mathrm{~mm}(150 \times 150$ DPI $)$ 